\title{
Comparison of dynamic flow models for the Central Aleutian and Tonga-Kermadec subduction zones
}

\author{
Magali I. Billen \\ Seismological Laboratory, California Institute of Technology, Pasadena, California 91125, USA \\ Now at Department of Geology and Geophysics, Woods Hole Oceanographic Institution, Mailstop 8, Woods Hole, \\ Massachusetts 02543, USA. (magali@whoi.edu)

\section{Michael Gurnis \\ Seismological Laboratory, California Institute of Technology, Pasadena, California 91125, USA (gurnis@gps.caltech.edu)}

[1] Using three-dimensional (3-D) instantaneous dynamic models of the Central Aleutian subduction zone, we show that a low viscosity, low density $\left(\delta \rho=10 \mathrm{~kg} / \mathrm{m}^{3}\right)$ region in the wedge is needed to match observations of topography, the geoid and the stress-state in the slab and overriding plate. Previous models of the Tonga-Kermadec subduction zone also require a low viscosity, low density $\left(\delta \rho=20 \mathrm{~kg} / \mathrm{m}^{3}\right)$ region in the wedge. A low viscosity region in the wedge decouples the overriding plate from the downward flow in the wedge caused by the sinking slab, reducing the magnitude of negative dynamic topography on the overriding plate and changing the state of stress in the slab from down-dip tension to down-dip compression. If the low viscosity region is large, as in the Tonga-Kermadec models, then the decoupling may also cause the overriding plate to go into extension. These are the first dynamic models to simultaneously match the state of stress in the slab and overriding plate and suggest that the combination of stress state within the slab and overriding plate may provide an additional constraint on the viscosity structure within subduction zones.

\footnotetext{
Components: 8035 words, 10 figures, 1 table.

Keywords: Viscosity; water; stress; mantle-wedge; topography; geoid.

Index Terms: 8120 Tectonophysics: Dynamics of lithosphere and mantle—general; 8162 Tectonophysics: Evolution of the Earth: Rheology—mantle; 8168 Tectonophysics: Evolution of the Earth: Stresses—general.

Received 12 December 2001; Revised 11 November 2002; Accepted 20 January 2003; Published 11 April 2003.

Billen, M. I., and M. Gurnis, Comparison of dynamic flow models for the Central Aleutian and Tonga-Kermadec subduction zones, Geochem. Geophys. Geosyst., 4(4), 1035, doi:10.1029/2001GC000295, 2003.
}

\section{Introduction}

[2] The Central Aleutian and the Tonga-Kermadec subduction zones have been the location of active subduction of the Pacific Plate since approximately 45 Ma. However, several observations show that the state of stress within the subducting and over- riding plates in these two subduction zones are very different. The upper plate of the Central Aleutian subduction zone consists of old $(\sim 120$ Ma) oceanic lithosphere (Bering Sea) between the island arc and continental lithosphere to the northeast and northwest [Cooper et al., 1976; Worrall, 1991]. Beyond the narrow ( $100 \mathrm{~km})$, high top- 

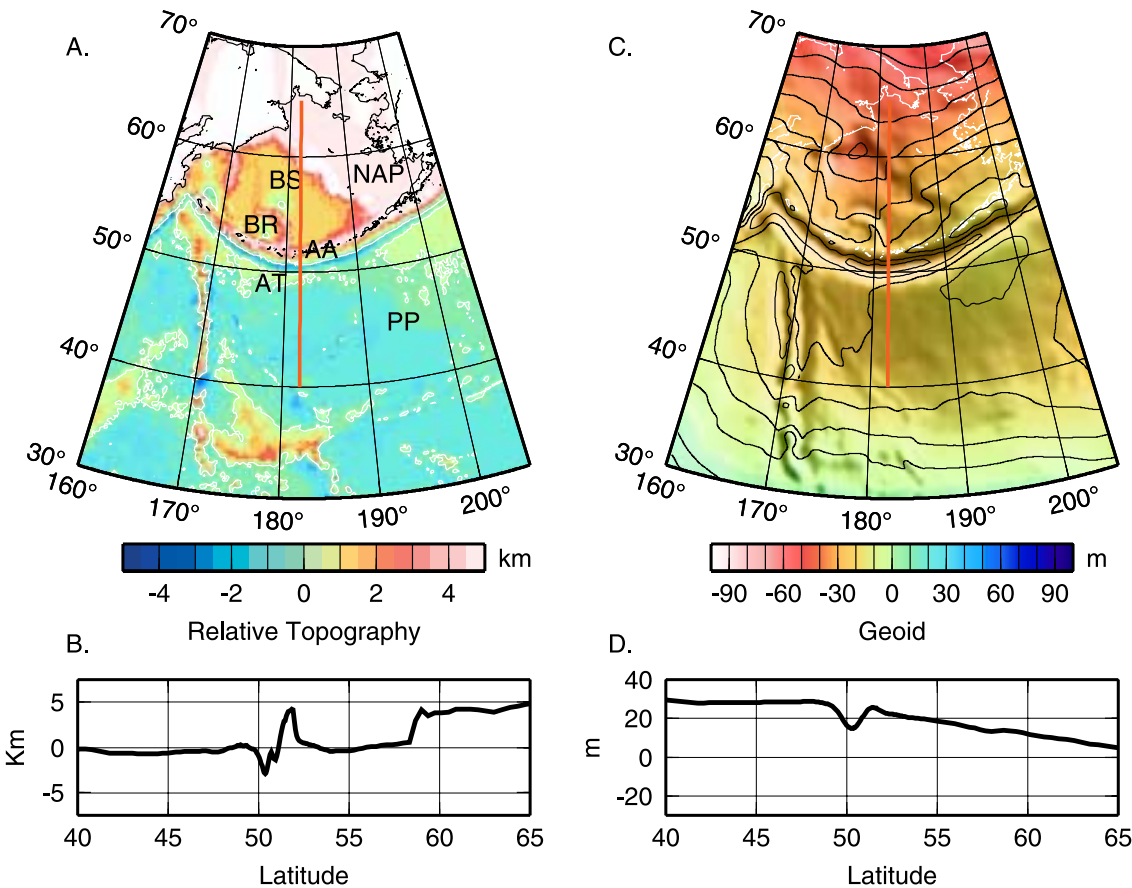

Figure 1. Central Aleutians. (a) Observed bathymetry (GEBCO, General bathymetric chart of the oceans, British Oceanographic Data Centre, computer file, 1997.) corrected for sediment thickness [Schroeder, 1984] and shifted up by $5 \mathrm{~km}$ for comparison with model results. This places abyssal hill depths on the Pacific Plate at $\sim 0 \mathrm{~km}$. Red line indicates location of profile in Figure 1b AT, Aleutian Trench; AA, Aleutian Arc; BR, Bowers Ridge; BS, Bering Sea; NAP, North American Plate; PP, Pacific Plate. (b) North-south profile of bathymetry at $182^{\circ}$. (c) Observed geoid [Lemoine et al., 1998]. Contour interval for the geoid is $10 \mathrm{~m}$. Red line indicates location of profile in Figure 1d. (d) North-south profile of the geoid at $182^{\circ}$. Profile has been shifted up for comparison with model results.

ography along the Aleutian Island Arc, the surface of the oceanic crust has an average depth of $8 \mathrm{~km}$ below a uniform layer of sediment greater than $4 \mathrm{~km}$ thick (Figures 1a and 1b). The geoid is marked by a narrow low over the trench and high over the back-arc and decreases steadily away from the back-arc on the overriding plate with a total change in height of only 20-30 m (Figures $1 \mathrm{c}$ and 1d). There is no evidence for extension within the overriding plate. Seismicity within the slab extends to only $250-300 \mathrm{~km}$ depth, shallowing to the west and east (Figure 2a). To the east, where the dip of the slab is shallow $\left(25^{\circ}\right)$, the slab appears to be in down-dip tension. However, in the Central Aleutian
A. Central Aleutians

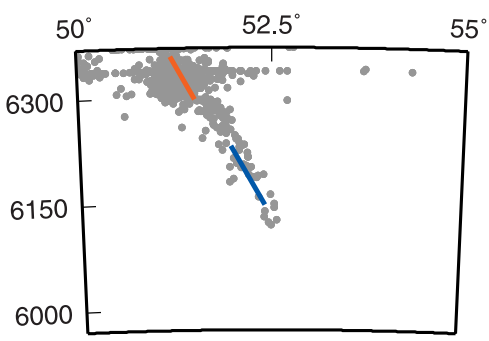

B. Tonga Kermadec

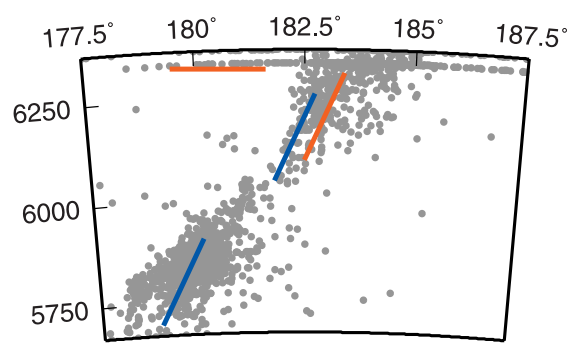

Figure 2. (a) North-south cross section of earthquake locations for Central Aleutians at $182^{\circ}$. Red and blue bars indicate regions of tension and compression, respectively (based on Astiz et al. [1988] and Lay et al. [1989]). (b) Eastwest cross section of earthquake locations for Tonga-Kermadec at $28^{\circ} \mathrm{S}$. Red and blue bars indicate regions of tension and compression, respectively (based on Kawakatsu [1986] and Seno and Yamanaka [1998]). 

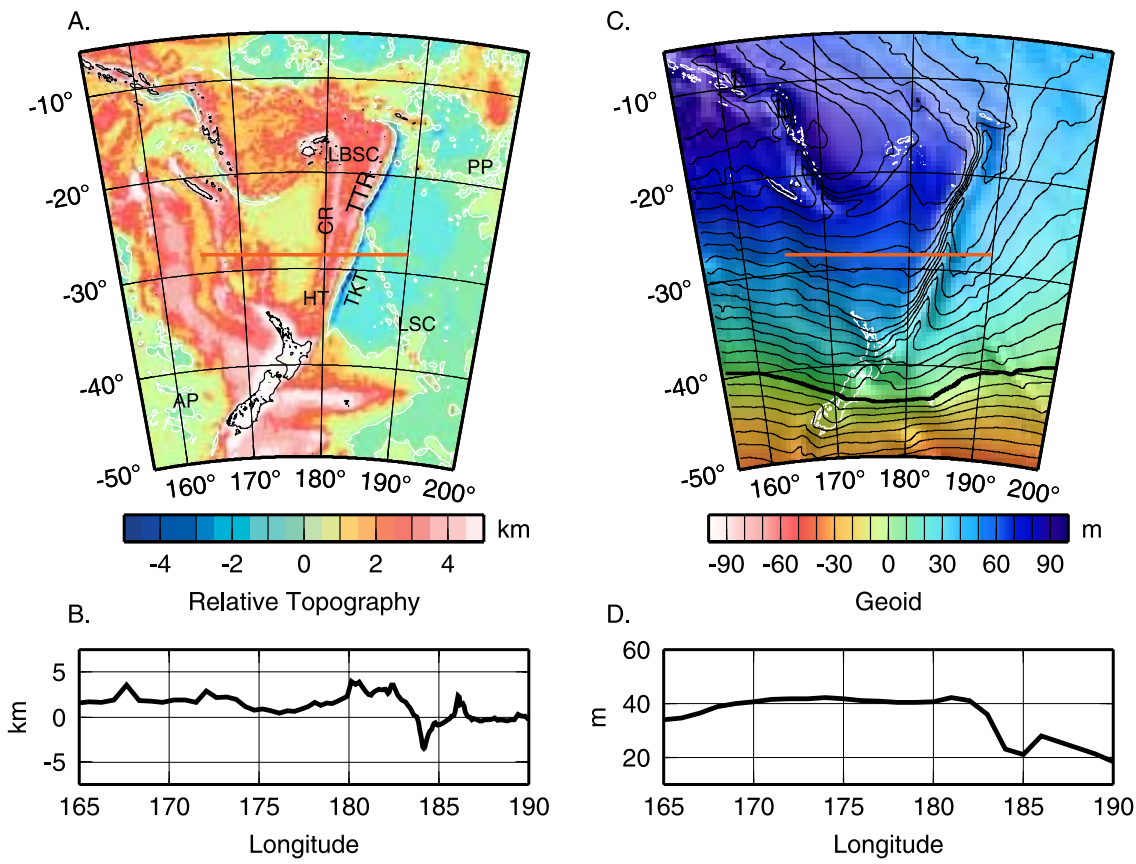

Figure 3. Tonga-Kermadec Subduction Zone. (a) Observed bathymetry (GEBCO, General bathymetric chart of the oceans, British Oceanographic Data Centre, computer file, 1997.) shifted up by $5 \mathrm{~km}$ for comparison with model results. This places abyssal hill depths on the Pacific Plate at $\sim 0 \mathrm{~km}$. Red line indicates location of profile in Figure 3b. TKT, Tonga-Kermadec Trench; LSC, Louisville Seamount Chain; TTR, Tonga-Tofua Arc; CR, Coleville Ridge; LBSC, Lau Back-arc Spreading Center; HT, Havre Trough; AP, Australian Plate; PP, Pacific Plate. (b) East-west profile of bathymetry at $28^{\circ} \mathrm{S}$. (c) Observed geoid [Lemoine et al., 1998]. Contour interval is $10 \mathrm{~m}$ (Thick line - zero contour). Red line indicates location of profile in Figure 3d. (d) East-west profile of the geoid at $28^{\circ} \mathrm{S}$. Profile has been shifted up for comparison with model results.

segment, where the slab dip increases to $60^{\circ}$, the slab is in down-dip tension only at very shallow depths $(100 \mathrm{~km})$, transitioning to down-dip compression at around $150 \mathrm{~km}$ [Astiz et al., 1988; Lay et al., 1989].

[3] In contrast, the Tonga-Kermadec subduction zone is characterized by active back-arc spreading, a deep trench $(6-10 \mathrm{~km})$, shallow bathymetry on the overriding plate $(2.5 \mathrm{~km})$, and large positive geoid $(40-100 \mathrm{~m})$ extending 1000 to $2500 \mathrm{~km}$ from the trench on the overriding plate (Figure 3 ). These observations indicate that the overriding plate is in horizontal extension and may be experiencing regional uplift [Scholl and Herzer, 1992] despite the dense slab beneath, which would tend to depress back-arc topography. The maximum depth of the Wadati-Benioff zone increases from $\sim 300 \mathrm{~km}$ in the south to at least $670 \mathrm{~km}$ north of $28^{\circ} \mathrm{S}$ (Figure $2 \mathrm{~b}$ ). The stress state within the slab, based on earthquake mechanism, also varies along strike with predominately down-dip compression at all depths in the north and a combination of downdip compression and tension in the south [Kawakatsu, 1986; Seno and Yamanaka, 1998].

[4] The different state of stress observed in the Central Aleutians (weak down-dip compression and down-dip tension in the slab with no backarc extension) and Tonga-Kermadec (strong downdip compression in the slab with back-arc extension) illustrates the range of stress states observed in all subduction zones, which include every combination of extension and compression within the overriding plate and the slab [Seno and Yamanaka, 1998]. Several models have been proposed to explain the stress state within the overriding plate [Chase, 1978; McKenzie, 1969; Scholz and Campos, 1995] or the slab [Astiz et al., 1988; Fujita and Kanamori, 1981; Houseman and Gubbins, 1997; Lay et al., 1989; Vassiliou et al., 1984]; however, a single explanation for the combinations of stress found in subduction zones has not yet been found. 
[5] One of the major difficulties in reproducing the wide variation in the combination of stress states has been predicting down-dip compressional stresses at shallow to intermediate $(100-300 \mathrm{~km})$ depths in the slab. Vassiliou et al. [1984] showed that the most commonly observed state of stress within the slab, shallow down-dip tension with deep down-dip compression, is the expected state of stress for a moderately strong slab sinking into the mantle and meeting resistance due to an increase in viscosity near $670 \mathrm{~km}$ depth. Houseman and Gubbins [1997] demonstrated that down-dip compression at shallow depths within the slab is expected if a strong slab is decoupled from the surrounding asthenosphere, allowing bending stresses within the slab, due to viscous flexure, to control the deformation of the slab. However, none of the approaches used in these models could simultaneously address the state of stress within the overriding plate and the slab, either because the overriding plate was modelled as a rigid plate [e. g., Vassiliou et al., 1984] or the slab was explicitly decoupled from the surrounding asthenosphere and the overriding plate [e. g., Houseman and Gubbins, 1997].

[6] Most previous models used to explain the causes of back-arc spreading have relied on force balance calculations in which the influence of slab induced flow on the overriding plate is parameterized in terms of coupling within the lithosphere and ignored the forces on the base of the lithosphere caused by flow within the wedge. Numerical models of instantaneous Stokes flow demonstrate that the slab beneath the overriding plate drags the overlying wedge down and towards the slab and therefore transmits large stresses to the overriding plate [Sleep, 1975; Zhong and Gurnis, 1994; Zhong et al., 1998]. The flow induced by the slab in the wedge pulls down on the overlying asthenosphere and lithosphere putting the overriding plate into compression and creating a broad (200-500 km), deep (3-4 km) basin in the back-arc region. Sleep [1975] found that in order to match the topography and gravity signal on the overriding plate in 2-D models of the Central Aleutian subduction zone, it was necessary to include a local region of low viscosity within the wedge beneath the island arc. However, a good match to both the gravity and topography was not found, in part because the plate boundary was incorporated as a wide shear zone and a very dense slab was needed to match the trench depth. Zhong and Gurnis [1994] and Zhong et al. [1998] showed that trench morphology and depth can be predicted without increasing the slab density by including a fault along the subduction boundary, but did not explore the role of localized regions of low viscosity.

[7] Here we present 3-D instantaneous, Stokes flow models for the Central Aleutian subduction zone. The models include a faulted plate boundary, radial- and temperature-dependent viscosity, and localized regions of low viscosity and/or low density (independent of temperature) within the wedge above the slab. We use observations of dynamic topography, the geoid, and stress within the slab and overriding plate to constrain the viscosity and buoyancy structure within the subduction zone. We find that it is necessary to include a small, low viscosity and low density region above the slab to match both the dynamic topography and the geoid and in doing so are still able to match the state of stress within the slab and overriding plate. In similar modeling carried out for the Tonga-Kermadec subduction zone [Billen and Gurnis, 2001, 2003], it was found that a large low viscosity, low density region was required to fit the observations. We will first present the new models for the Central Aleutians. We will then summarize the previous results for the Tonga-Kermadec subduction zone and show that the presence of a low viscosity region within the wedge provides a single explanation for several geophysical and geochemical observations characterizing both subduction zones.

\section{Numerical Method}

[8] We investigate the influence of local variations in viscosity and buoyancy on the dynamics of a subduction zone using a finite element model for instantaneous viscous flow. Assuming that inertial forces are negligible and applying the Boussinesq approximation, the equations of motion for flow caused by internal buoyancy anomalies are

$$
\nabla \cdot \mathbf{u}=0
$$


and

$$
\nabla \cdot \sigma+\mathbf{f}=0
$$

where $\mathbf{u}, \mathbf{f}$ and $\sigma$ are the flow velocity, the body force and stress tensor, respectively. The body force includes density anomalies due to temperature $T$,

$$
f_{i}=\rho_{o} \alpha\left(T-T_{o}\right) g \delta_{i r}
$$

where $\rho_{o}$ is the reference density, $T_{o}$ is reference temperature, $g$ is the gravitational acceleration, $\alpha$ is the coefficient of thermal expansion and $\delta_{i j}$ is Kronecker delta. Inferred density variations due to composition are included in terms of an equivalent temperature anomaly. The equations are solved with a primitive variable formulation using CitcomT [Billen and Gurnis, 2003] a 3-D, spherical geometry finite element code based on the Cartesian code Citcom [Moresi and Solomatov, 1995; Moresi and Gurnis, 1996; Zhong et al., 1998]. The code has been tested extensively and validated with analytic solutions for flow and topography with large radial and lateral variations in viscosity [Billen and Gurnis, 2003].

[9] The model domain extends from the surface to the core-mantle boundary, $45^{\circ}$ in longitude $\left(160^{\circ}-200^{\circ}\right)$ and $40^{\circ}$ in latitude $\left(30^{\circ} \mathrm{N}-70^{\circ} \mathrm{N}\right)$. The top and bottom surfaces have free-slip, isothermal boundary conditions. The side-walls, defined as planes of equal longitude or latitude, have no shear stress boundary conditions. Element size ranges from $2.5 \mathrm{~km}$ within the wedge, slab and upper $200 \mathrm{~km}$ of the model, to $100 \mathrm{~km}$ at the side boundaries and in the lower mantle. A fault along the subduction zone boundary is modelled with boundary conditions requiring continuous normal velocity, but allowing discontinuous tangential velocities across the fault interface [Zhong and Gurnis, 1994; Zhong et al., 1998]. While the true dip of the fault at the surface ranges from $10^{\circ}-30^{\circ}$, due to numerical constraints on distortion of the rectangular elements, the maximum dip of the fault within the top $10 \mathrm{~km}$ is $30^{\circ}$.

[10] The geophysical observations of topography, geoid, and stress orientations provide direct con- straints on the present day structure of the subduction zone. Therefore, we use instantaneous models in which the geometry of the subduction zone is constrained by topography at the surface and earthquake locations in the subsurface. This approach requires that the thermal structure for the lithosphere and slab is specified. This thermal structure is then used to define the density and viscosity structure.

[11] The thermal structure of the slab is derived from a kinematic model of flow constrained to follow the location of the slab, delineated by seismicity, from the surface to the maximum depth of seismicity $(300 \mathrm{~km})$. The flow field consists of a corner flow above and below the top surface of the slab (including the subducting lithospheric plate) and a fixed overriding plate. The starting temperature for the kinematic model is defined by a halfspace cooling model for each plate based on its estimated age at the beginning of subduction [Cooper et al., 1976; Müller et al., 1997; Worrall, 1991]. The background thermal structure for the present-day slab is found by solving the advectiondiffusion equation with the fixed flow field until steady-state is reached (Figure 4a) [see Billen and Gurnis, 2003]. Instantaneous flow is driven by internal buoyancy sources due to the thermal structure, including the slab and variations in lithosphere age, and chemical heterogeneities, including crustal thickness variations within the island arc and continents and variations in mineralogy and melt content in the wedge above the slab. The maximum density anomaly within the slab is $+66 \mathrm{~kg} / \mathrm{m}^{3}$ assuming the values listed in Table 1. Crustal density anomalies are assumed to be $-500 \mathrm{~kg} / \mathrm{m}^{3}$.

[12] Density variations due to melting processes within the wedge are not well known. However, low density regions with density differences up to $20 \mathrm{~kg} / \mathrm{m}^{3}$, due to large melt fraction within and at the base of the crust beneath the island arc, are not unreasonable [Rigden et al., 1984]. Low density regions may occur deeper in the wedge due to high degrees of melting of peridotite [Stolper and Newman, 1994] expected due to high concentrations of water within the wedge, derived from dehydration reactions within the subducting slab [Morris et al., 
A.

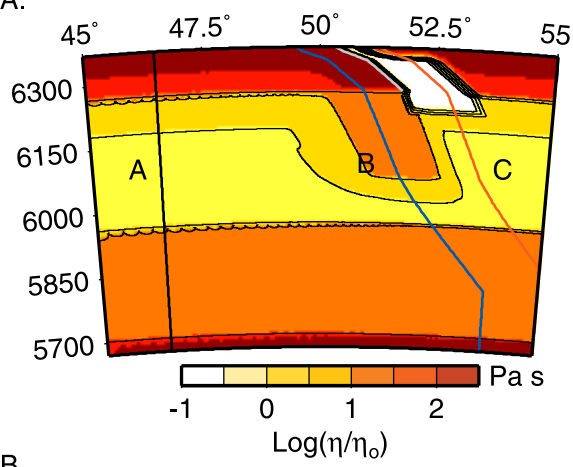

B.

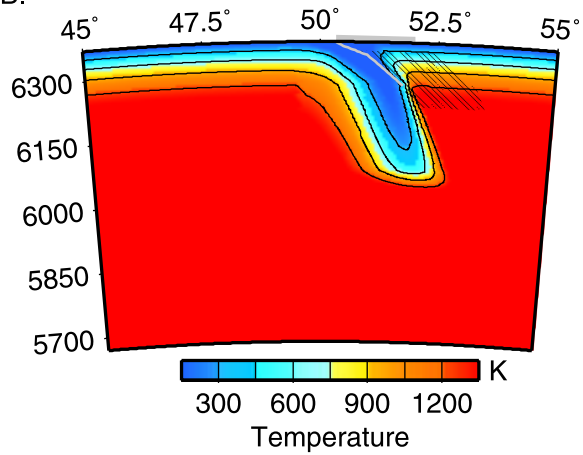

C. Viscosity Profiles

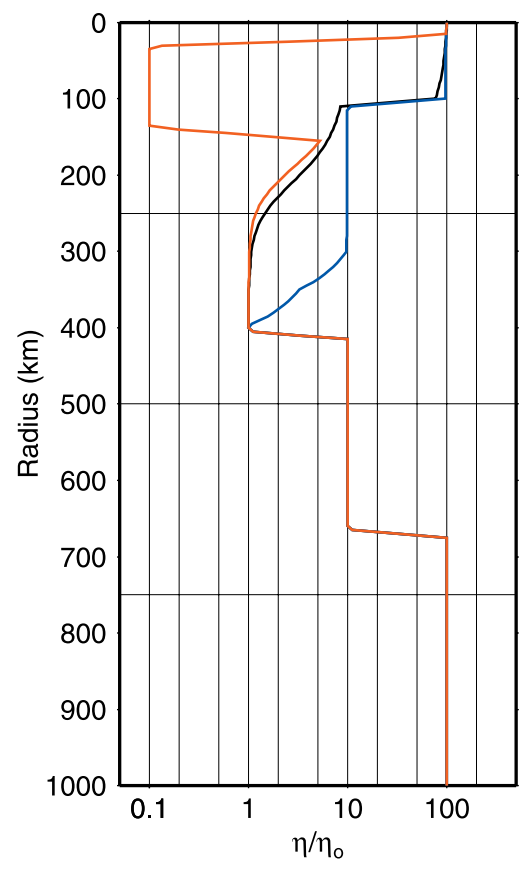

Figure 4. Cross section of model structure for Central Aleutians at $182^{\circ}$. (a) Viscosity including LVW and shear zone above the fault. Vertical lines indicate location of depth profiles plotted in Figure 4c: A (black), background profile; B (blue), slab profile; C (red), wedge profile. (b) Temperature field with location of crustal density anomalies (gray boxes) and wedge buoyancy (hatched region). (c) Depth profiles of viscosity: black, background profile; blue, slab profile; red, wedge profile.

1990; Schmidt and Poli, 1998; Tatsumi et al., 1983]. Less garnet forms within the garnet stability field $(P>30 \mathrm{kbar})$ in highly depleted peridotite due to the loss of $\mathrm{Al}_{2} \mathrm{O}_{3}$, leading to a decrease in density, compared to fertile peridotite, by up to $50 \mathrm{~kg} / \mathrm{m}^{3}$, for $30 \mathrm{wt} \%$ melting (P. Asimow, personal communication, 2001).

[13] The background viscosity structure consists of four layers: lithosphere $(0-100 \mathrm{~km})$, asthenosphere $(100-410 \mathrm{~km})$, transition zone $(410-670 \mathrm{~km})$ and lower mantle $(670-2890 \mathrm{~km})$. Viscosity is temperature dependent with the maximum viscosity in each layer defined with respect to a reference viscosity $\eta_{o}$ with a value of $3 \times 10^{20} \mathrm{~Pa}$ s: lithosphere $\left(\eta_{\text {lith }}=100 \times \eta_{o}\right)$, asthenosphere $\left(\eta_{\text {asth }}=\eta_{o}\right)$, transition zone $\left(\eta_{\text {tran }}=10 \times \eta_{o}\right)$ and lower mantle $\left(\eta_{l m}=100 \times \eta_{o}\right)$. The maximum viscosity of the slab at all depths is $100 \times \eta_{o}$ (Figure 4B and 4C).

[14] A low viscosity region within the wedge (LVW) may be caused by high concentrations of water [Mei, 1999; Karato, 2003] or melt at shallow depths [Hirth and Kohlstedt, 1995, 1996; Kelemen et al., 1997; Phipps-Morgan, 1997]. Seismic observations in several subduction zones show regions of low seismic velocity within the wedge extending from the base of the crust to greater than $200 \mathrm{~km}$ [Hasegawa et al., 1991; Roth et al., 2000; Zhao et al., 1992]. These deep seismic anomalies may be caused by the presence of water [Karato, 2003]. In the Central Aleutians, seismic refraction data are consistent with a region of slow seismic velocity in

Table 1. Model Parameters

\begin{tabular}{ll}
\hline \multicolumn{1}{c}{ Variable Name } & \multicolumn{1}{c}{ Value } \\
\hline Reference density, $\rho_{o}$ & $3300 \mathrm{~kg} / \mathrm{m}^{3}$ \\
Temperature difference from & $1500 \mathrm{~K}$ \\
$\quad$ top to bottom surface, $\Delta T$ & $1 \times 10^{-6} \mathrm{~m}^{2} / \mathrm{s}$ \\
Thermal diffusivity, $\kappa$ & $2 \times 10^{-5} \mathrm{~K}^{-1}$ \\
Coefficient of thermal expansion, $\alpha$ & $6371.137 \mathrm{~km}$ \\
Earth radius, $R$ & $10 \mathrm{~m} / \mathrm{s}^{2}$ \\
Gravitational acceleration, $g$ & $3 \times 10^{20} \mathrm{~Pa} \mathrm{~s}$ \\
Reference viscosity, $\eta_{o}$ & $8.53 \times 10^{8}$ \\
Rayleigh number, $R a$ & \\
\hline
\end{tabular}




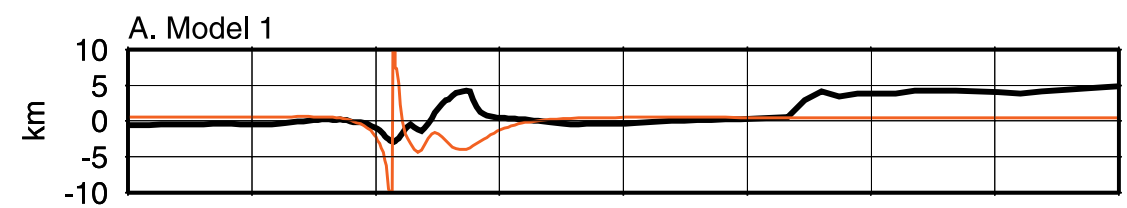

B. Model 2

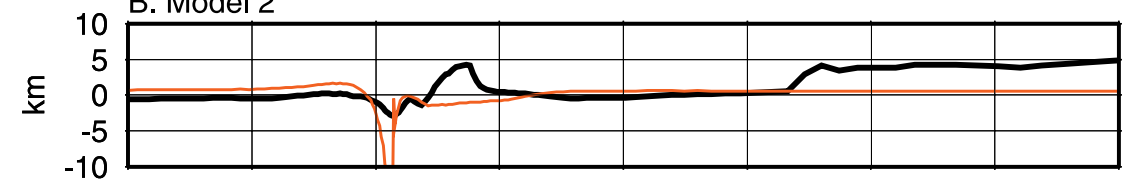

C. Model 3
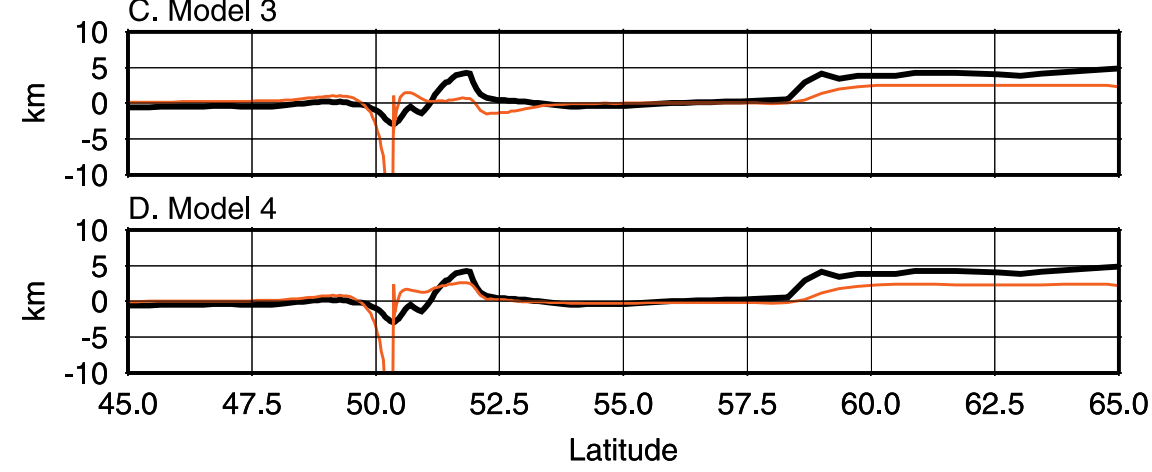

Figure 5. Comparison of residual topography (black-thick, see text for calculation of residual topography) and predicted (red-thin) dynamic topography for north-south cross sections at $182^{\circ}$. (a) Model 1, radial- and temperaturedependent viscosity. (b) Model 2, includes a low viscosity region in the wedge (LVW) and a narrow shear zone along the plate boundary fault. (c) Model 3, includes crustal thickness variations for the active island arc, Bowers Ridge and continental regions. (d) Model 4, includes low density region coincident with the $\operatorname{LVW}\left(\Delta \rho=10 \mathrm{~kg} / \mathrm{m}^{3}\right)$.

a narrow region parallel to the slab from beneath the island arc to depths of $100 \mathrm{~km}$ [Grow, 1973]. Seismic tomography in the Shumagin area of the arc reveal slow seismic velocity regions within the crust beneath the island arc and extending into the wedge [Abers, 1994]. In models including a low viscosity wedge, this viscosity variation is superimposed on the temperature-dependent viscosity structure.

[15] Dynamic topography, geoid height and stress orientations are compared with observations to assess the success of each viscosity and buoyancy model. Because the overriding plate within the Bering Sea is covered with thick sediments $(>4 \mathrm{~km})$ it is necessary to correct the observed topography for the sediment load. The sediments could be incorporated in the dynamic model as an effective density anomaly on the overriding plate. However, since these density anomalies do not contribute to uncompensated topography (i. e., do not change mantle flow) and it is straightforward to correct for the influence of the sediments on topography, we calculate a residual topography for comparison with the predicted dynamic topography from the models [Gurnis et al., 2000]. We use bathymetry data based on ship track data measurements for the observed topography (GEBCO, General bathymetric chart of the oceans, British Oceanographic Data Centre, computer file, 1997). We then subtract the thickness of the sediments on the overriding plate [Laske and Masters, 1997] and, assuming local isostasy, correct for the change in depth of the seafloor due to the weight of the sediments [Schroeder, 1984]. Using this approach, dynamic topography away from the active subduction zone margin is approximately zero (Figure 5).

[16] We calculate the predicted geoid using spherical harmonic functions and include contributions from dynamic topography on the surface and coremantle boundary and density anomalies within the mantle. This method implicitly assumes that there are no density anomalies outside the model domain. This means that topography outside the model is zero and any topography on the top or bottom surface of the model along the side-walls will create a step in topography across the side 
boundaries, leading to large short wavelength noise in the predicted geoid. To minimize any offset in topography across the model side-wall boundaries, we taper crustal density anomalies to zero within $5^{\circ}$ of the domain boundaries, set the age of the lithosphere along the boundaries to $100 \mathrm{Ma}$ and shift the predicted topography everywhere by the mean value along the edge of the domain.

[17] The trench depth in the models is much larger than observed due to a stress singularity at the fault tip that increases with decreasing element size. Since we use small elements along the top surface of the slab to accurately model sharp viscosity boundaries, the stress singularity in the models leads to trench depths of greater than $15 \mathrm{~km}$. In calculating the contribution to the geoid due to topography we limit the maximum depth of the trench to $5 \mathrm{~km}$ relative to the average depth of the subducting plate. The stress singularity also creates a large peak in topography in the fore-arc on the overriding plate. Including a weak zone above the fault $(20 \mathrm{~km}$ wide perpendicular to the fault) simulating the highly faulted, weak accretionary wedge in the fore-arc reduces this peak to $1-2 \mathrm{~km}$.

[18] The observed geoid within the model domain includes large long wavelength signal from processes not included in the subduction zone models (Figure 1). Therefore, we compare the observed geoid to the predicted geoid using a spatio-spectral localization method [Simons, 1996]. This method allows us to calculate the position and wavelength (or harmonic degree) dependent correlation between the observed and predicted geoid. We then limit our analysis to wavelengths smaller than half the size of the domain $(2000 \mathrm{~km})$ and larger than twice the size of the largest element $(200 \mathrm{~km})$. Using this method we can limit the analysis to signal within the region of the model caused by processes included in the model.

\section{The 3-D Models of the Central Aleutian Subduction Zone}

[19] The observed topography across the Central Aleutian subduction zone includes a small forebulge (200-300 m), a small (2.5 km deep) narrow
$(50 \mathrm{~km})$ trench, a fore-arc high immediately adjacent to the trench and a narrow region of high topography $(4 \mathrm{~km})$ along the island arc. Model 1 which includes only radial- and temperaturedependent viscosity predicts a large topographic basin over the island arc region (Figures $5 \mathrm{a}$ and $6 \mathrm{~b})$. The abrupt change in dip of the fault from $30^{\circ}$ to $60^{\circ}$ at a depth of $50 \mathrm{~km}$ focuses stress above it creating the small bump within the basin. The overriding plate is in compression in a $300 \mathrm{~km}$ wide region above the slab (Figure 7a). Further from the slab the overriding plate is in tension, but this is due to boundary conditions on the flow with zero horizontal velocity at the model boundaries (Figure $7 b$ ). The slab is in down-dip or vertical tension at all depths $(0-250 \mathrm{~km})$ except for the leading edge of the slab (deepest $25-50 \mathrm{~km}$ ) which is in down-dip compression. The large basin and compressional stress in the overriding plate are caused by coupling of the downward flow, caused by the sinking slab, to the overriding plate.

[20] The broad, deep basin creates a large geoid low above the back-arc and the long wavelength geoid is almost flat across the model domain (Figure 6a and Figures 8a-8d). The localized correlation between the observed and predicted geoid has a large negative correlation directly beneath the trench and back-arc region at all wavelengths. Beneath the forebulge on the subducting plate, positive correlations at short wavelengths $(<500 \mathrm{~km})$ indicate that this region of the model agrees with the observed geoid, despite the large misfit over the trench.

[21] Billen and Gurnis [2003] demonstrate that simply decreasing the asthenosphere viscosity relative to the slab and/or lithosphere does not decrease the size or depth of the basin on the overriding plate. Instead, a localized low viscosity region above the slab, which modifies the flow pattern in the wedge, is needed to decrease the basin size. In model 2 we include a low viscosity region parallel to the slab. The low viscosity region is $100 \mathrm{~km}$ wide from the top surface of the slab to the island-arc region and extending from a depth of $20 \mathrm{~km}$ to $150 \mathrm{~km}$. A narrow shear zone $(20 \mathrm{~km}$ wide) is also included above the fault from the surface to $20 \mathrm{~km}$ depth. The viscosity within the 

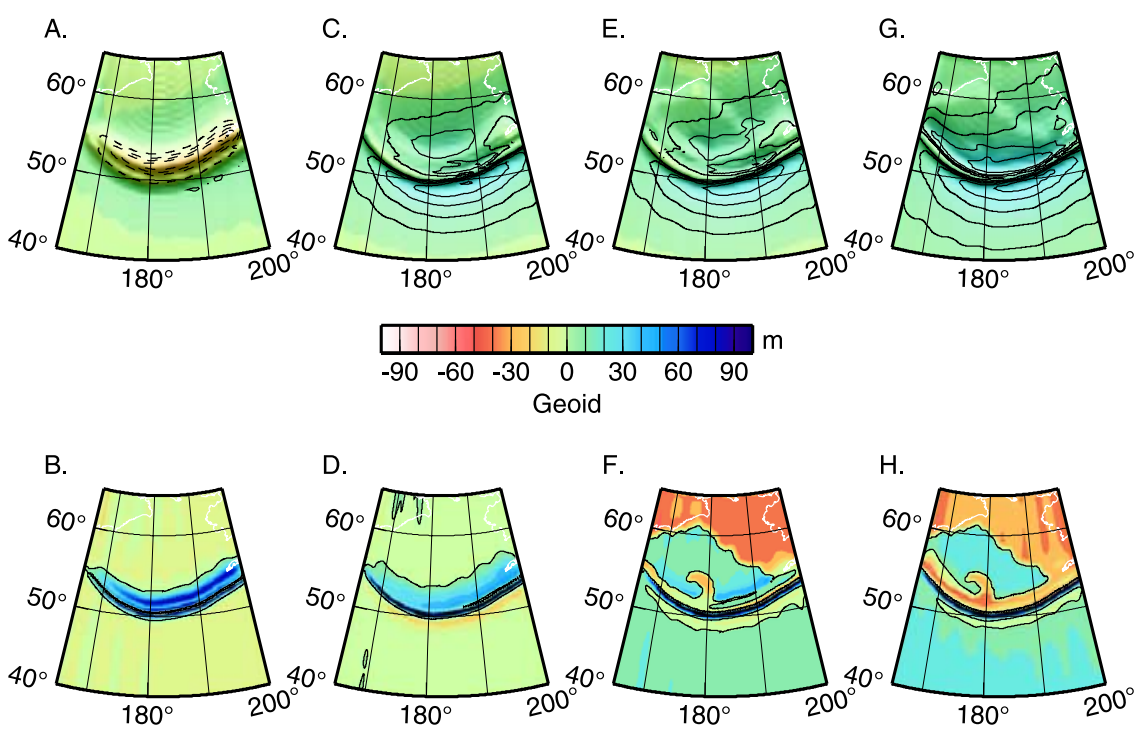

F.
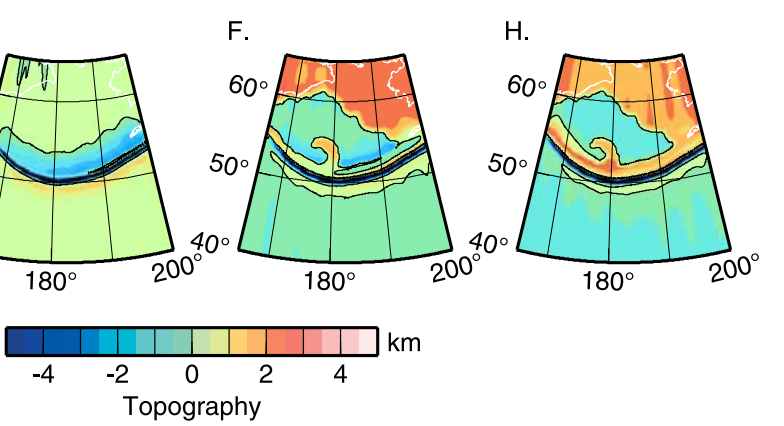

Figure 6. (a) Predicted geoid and (b) dynamic topography for model 1, (c, d) Model 2, (e, f) Model 3, and (g, h) Model 4. Contour interval for the geoid is $10 \mathrm{~m}$ (dashed, negative; solid, positive). Only part of the domain is shown here: $5^{\circ}$ is omitted on the east, west and north boundaries since age and crustal variation are not included along the edge of the model domain and $10^{\circ}$ is omitted on the south boundary since there is no variation in the topography or geoid in this region of the models.

LVW is $0.1 \times \eta_{o}$ and the viscosity of the shear zone is $\eta_{o}$. The LVW has a substantial effect on the topography of the overriding plate, almost completely eliminating the basin (Figures $5 \mathrm{~b}$ and $6 \mathrm{~d}$ ). The thick, strong lithosphere of the overriding plate is strongly coupled to the slab induced flow within the mantle requiring that the width of the LVW is at least as wide as the basin in Model 1. A narrower LVW would allow the basin to extend beyond the edge of the LVW furthest from the slab. A wider LVW would also decrease the basin depth; however, we found that a wider LVW produced small, short wavelength positive topography beyond the island arc region which is not observed. The overriding plate remains in horizontal compression above the low viscosity region, while the orientation of stress within the top of the slab $(25 \mathrm{~km}$ thick), deeper than $100 \mathrm{~km}$, is no longer in downdip tension (Figures $7 \mathrm{c}$ and $7 \mathrm{~d}$ ). Instead the principal compression directions are aligned with a dip approximately $20^{\circ}$ less than the local dip of the slab, rotating into down-dip compression between 200 and $300 \mathrm{~km}$. The interior and bottom of the slab remain in down-dip compression.
[22] By reducing the size of the basin, the large geoid low over the back-arc disappears and is replaced by a small, narrow geoid low directly over the trench with only a flattening out of the geoid over the island arc region (Figures $6 \mathrm{c}$ and $8 \mathrm{e}-8 \mathrm{~h}$ ). A long wavelength geoid high, with a peak amplitude of $25 \mathrm{~m}$, now dominates the geoid signal over the subduction zone. The higher correlations $(>0.8)$ obtained from the localization analysis confirm the improved agreement with the observations at wavelengths of $500 \mathrm{~km}$, except beneath the island arc where the geoid is less than observed. Although the slope of the geoid over the region north of the island arc is similar to observed, the correlations show that at both short and intermediate wavelengths this part of the geoid is still not well modelled. In the island arc region the mismatch at short wavelengths is probably caused by missing crustal density anomalies. North of the back-arc a small change in the slope of the observed geoid at $58^{\circ} \mathrm{N}$ coincides with the edge of the continental shelf in the Bering Sea.

[23] To improve the fit of the observed topography at short wavelengths, in model 3 we include 
A. Model 1

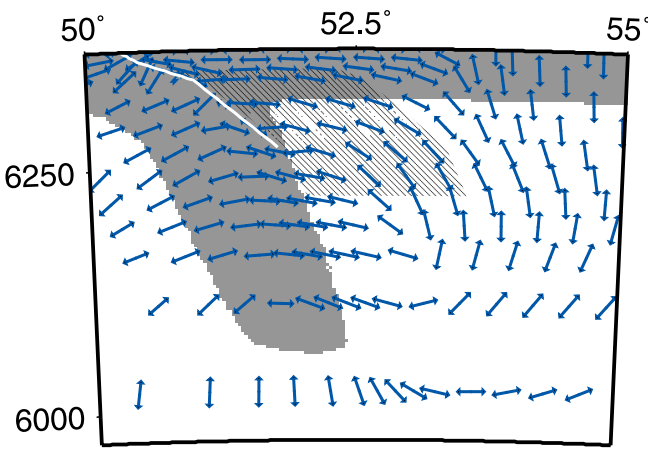

C. Model 2

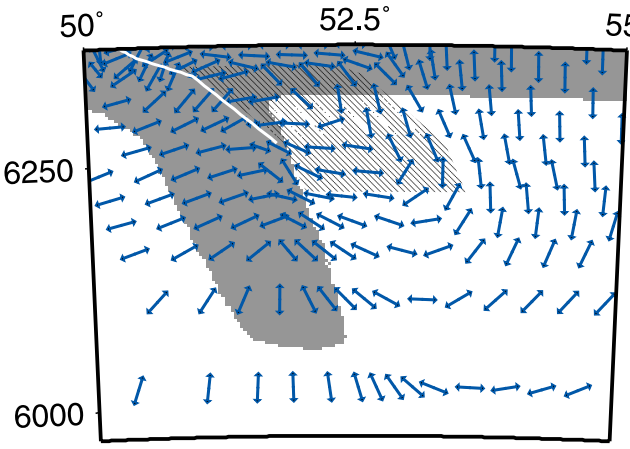

E. Model 3

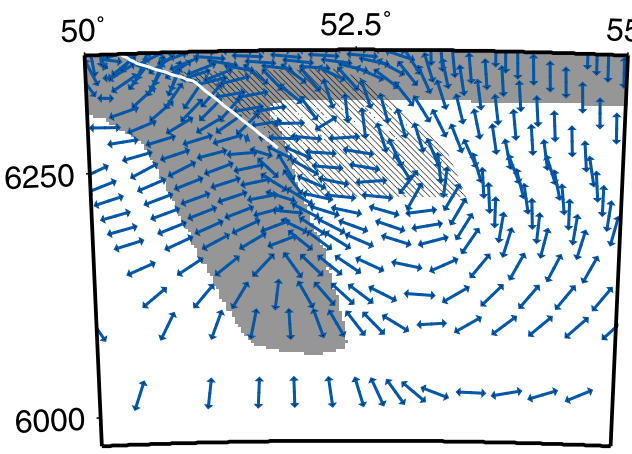

Principal Compression
B.

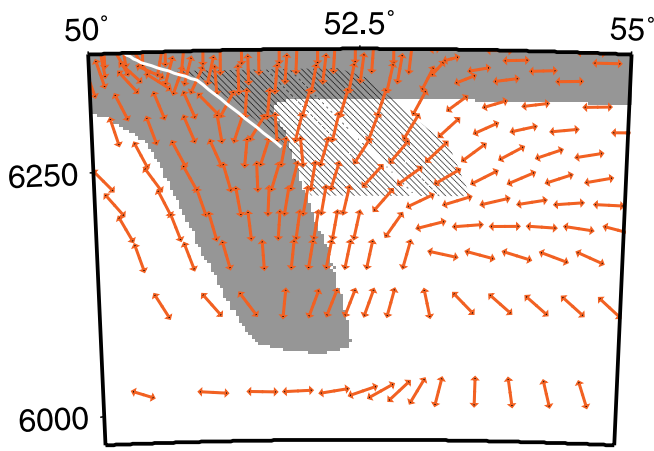

D.

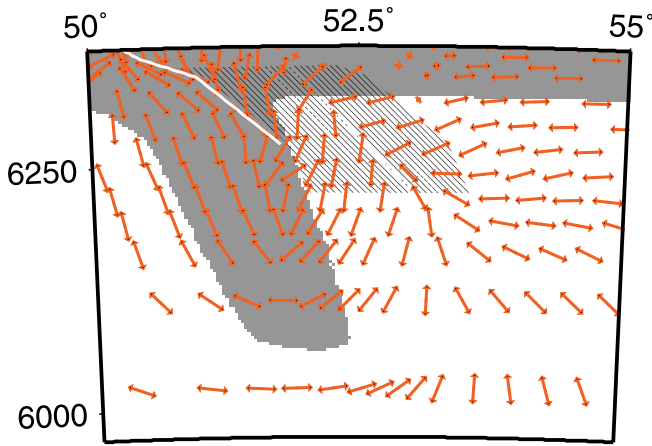

F.

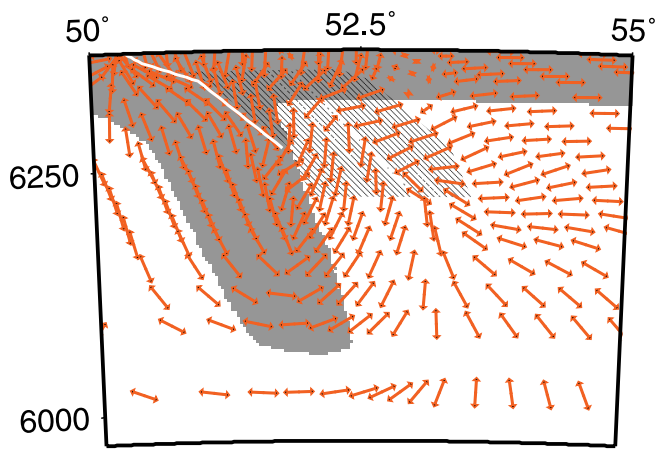

Principal Tension

Figure 7. North-south cross section of principal compression (blue) and tension (red) stress directions for Central Aleutians models projected into the plane of the cross section at $182^{\circ}$ : (a) Model 1, (b) Model 2, and (c) Model 3. Model 4 shown in Figures 10c and 10d.

density anomalies due to crustal thickness variations within the island arc $(18 \mathrm{~km})$, Bowers Ridge $(18 \mathrm{~km})$ and the continental regions $(20 \mathrm{~km})$. Including the continental crust improves the fit to both the observed topography (Figures $5 \mathrm{c}$ and $6 \mathrm{f}$ ) and the geoid (Figures 6e and 8i-81), although a larger thickness is probably needed: the predicted height of the continents is shallow by about $2 \mathrm{~km}$.
The crustal anomalies within the island arc create mild topography, but the amplitude is too small while a small basin forms behind the island arc where the observed topography increases as the far side of the island arc is approached. No observations indicate that other crustal anomalies should exist behind the island arc and the long wavelength character of the topography in the region suggests 


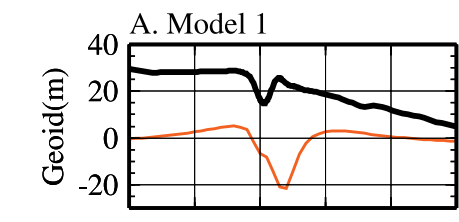

E. Model 2
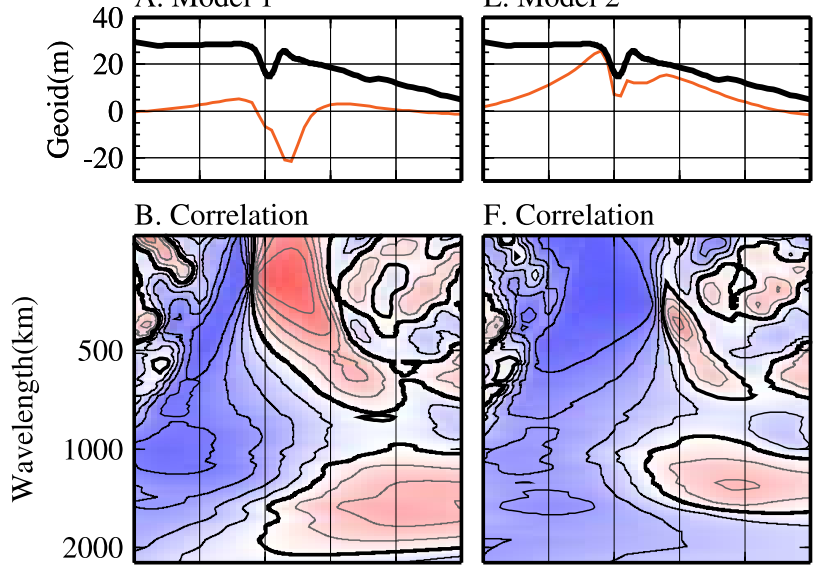

C. RMS Amplitude
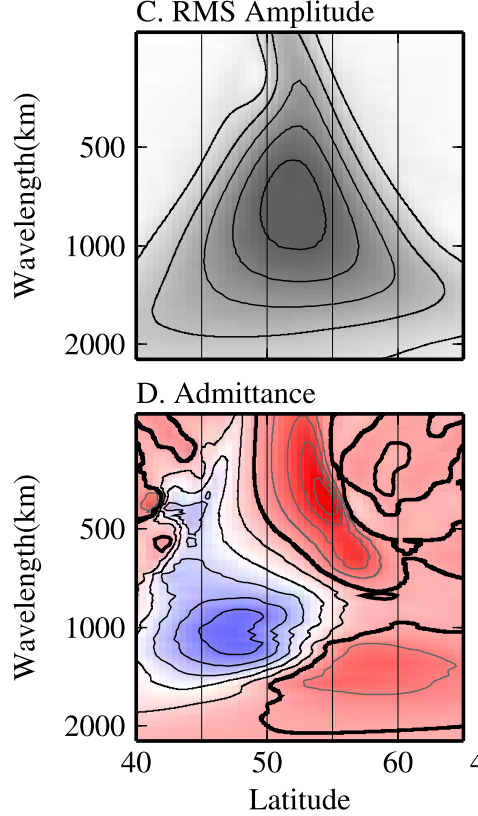

F. Correlation

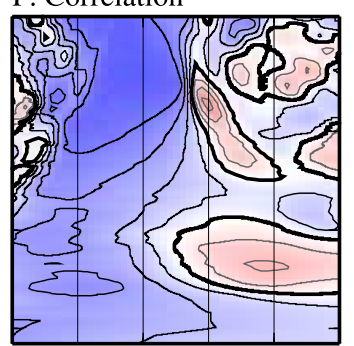

G. RMS Amplitude

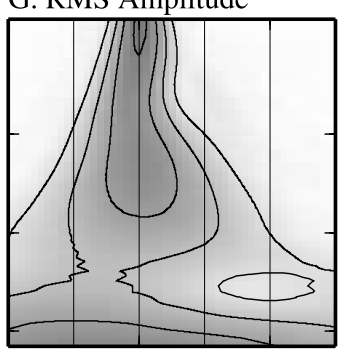

H. Admittance

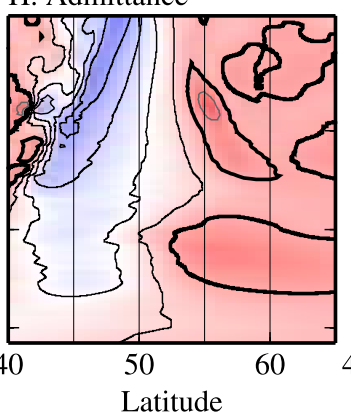

I. Model 3

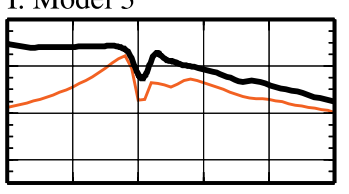

J. Correlation

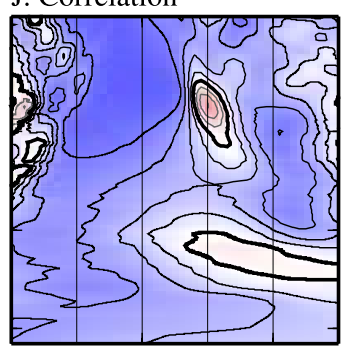

K. RMS Amplitude

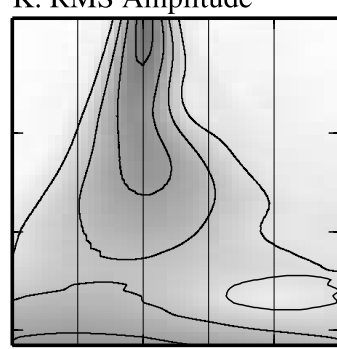

L. Admittance

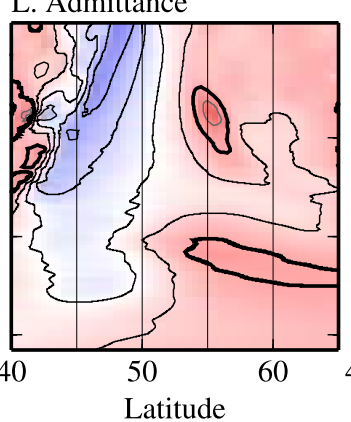

M. Model 4

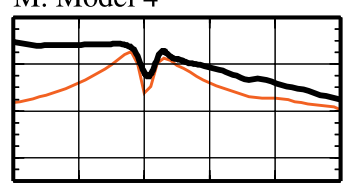

N. Correlation

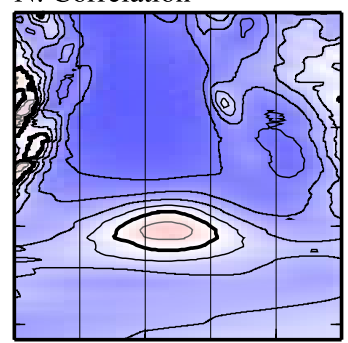

O. RMS Amplitude

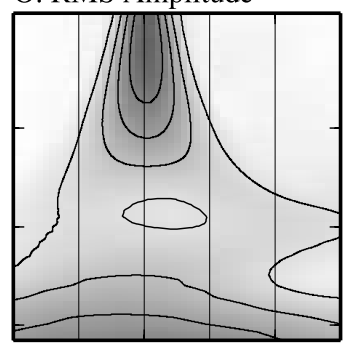

P. Admittance

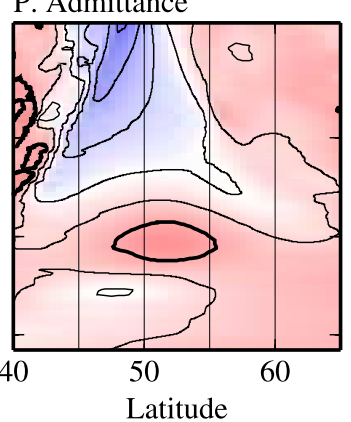

Figure 8. Geoid localization for north-south cross section at $182^{\circ}$. (a) Comparison of observed (black-thick line) and predicted (red-thin line) geoid for model 1. A north-south linear ramp is removed from the profiles for comparison. (b) Position and wavelength dependent correlation between observed and predicted geoid. Positive values are indicated by blue regions. Negative values are indicated by red regions. Zero contour is marked by the thick black contour. Contour interval is 0.2. (c) RMS amplitude of model geoid. Contour interval is 1. (d) Admittance. Positive values are indicated by blue regions. Negative values are indicated by red regions. Zero contour is marked by the thick black contour. Contour interval is 0.5. (e-h) Same for Model 2, (i-l) Model 3, and (m-p) Model 4.

that it is caused by a deeper source of buoyancy. The stress within the slab and overriding plate are unchanged from model 2 (Figures 7e and 7f).

[24] In model 4 we reduce the density within the LVW by $10 \mathrm{~kg} / \mathrm{m}^{3}$ compared to the surrounding asthenosphere and lithosphere. We did not vary the size of the low density region under the assumption that the low viscosity and low density are caused by coupled processes. The density anomaly within the
LVW was adjusted to fit the slope and amplitude of the topography behind the island arc. Including the low density region improves the fit to observed height of the island arc. The fore-arc topography is too high, but this may be due to crustal density anomalies in the model extending too far into the fore-arc region. The fore-arc is an accretionary prism made up of pieces of oceanic crust sliced off the subducting lithosphere [Grow, 1973] and therefore may not have a density as low as would be 
A.

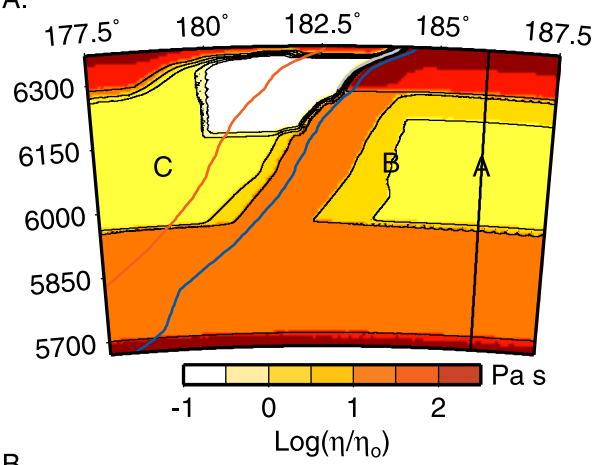

B.

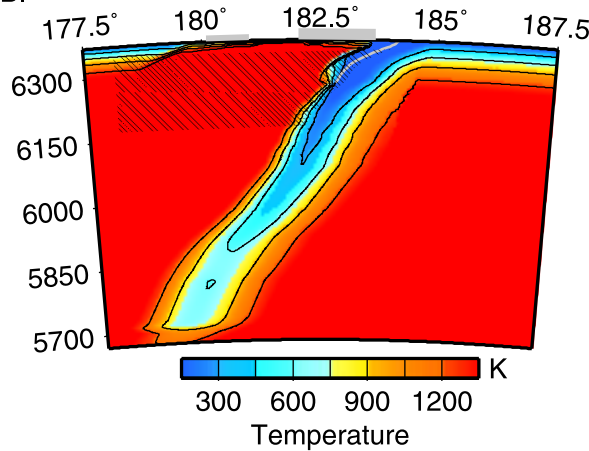

C. Viscosity Profiles

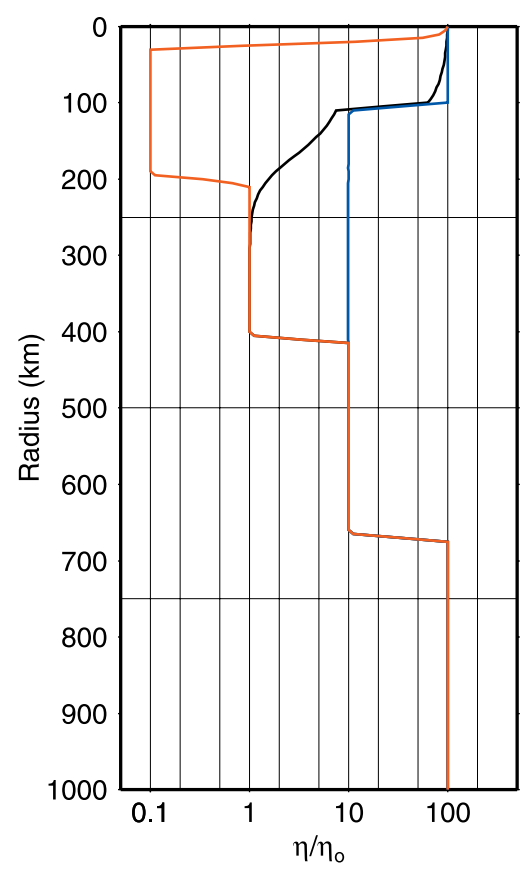

Figure 9. Cross section of model structure for Tonga-Kermadec at $28^{\circ} \mathrm{S}$. (a) Viscosity including LVW and shear zone above the fault. Vertical lines indicate location of depth profiles plotted in Figure 9c; A (black), background profile; B (blue), slab profile; C (red), wedge profile. (b) Temperature field with location of crustal density anomalies (gray boxes) and wedge buoyancy (hatched region). (c) Depth profiles of viscosity: black, background profile; blue, slab profile; red, wedge profile.

expected if the accretionary prism were composed of only sediments scraped off the subducting crust.

[25] The match to the observed geoid improves significantly. The cross section of the geoid (Figure $8 \mathrm{~m})$ shows a good match to the short wavelength low over the trench. The short wavelength high over the back-arc is slightly broader than observed and this probably reflects the misfit in the topography over the fore-arc. The region of positive correlation now spans the entire width of the subduction zone with values over 0.95 for wavelengths less than about $700 \mathrm{~km}$ (Figures $8 \mathrm{n}-8 \mathrm{p}$ ). The region of low or negative correlation at wavelengths of $1000 \mathrm{~km}$ highlights the difference in slope of the observed and predicted geoid at these wavelengths. While this can not be visually compared on the subducting plate side, above the overriding plate the slope of the predicted geoid increases more rapidly approaching the trench, than the observed geoid. This difference in slope and negative correlation at intermediate wave- lengths may indicate that the density of the slab in these models is too large.

[26] Low density within the wedge does not change the orientation of stress within the slab compared with model 2 or model 3; however, the orientation of stress within the overriding plate now includes a region of horizontal extension, limited to the region directly above the LVW, beneath the island arc, with horizontal compression in the fore-arc region (Figures 10c and 10d). The magnitude of extension decreases at the boundary of the LVW before reaching the region where there is extension controlled by the boundary conditions.

\section{Comparison to 3-D Models of the Tonga-Kermadec Subduction Zone}

[27] A low viscosity, low density region within the wedge is also needed to match observations of topography, geoid and stress for the Tonga-Kermadec subduction zone (Figure 9). The complex his- 


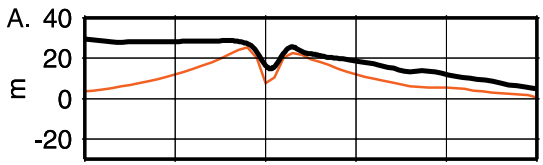

B.

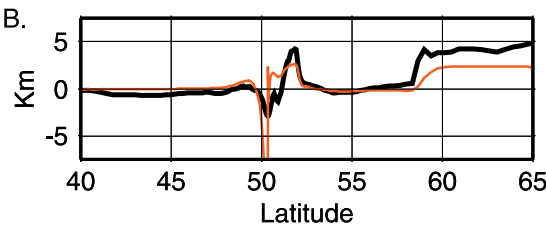

C. $50^{\circ}$

$52.5^{\circ}$

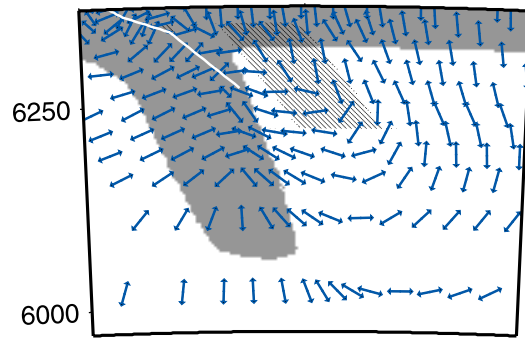

$55^{\circ} \mathrm{G}$

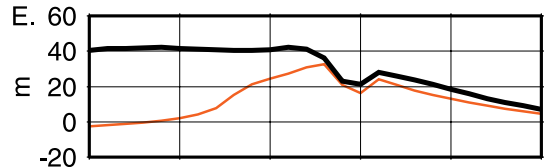

$\mathrm{F}$.

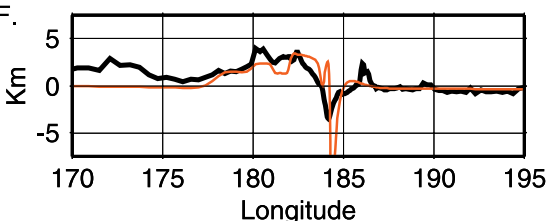

G.

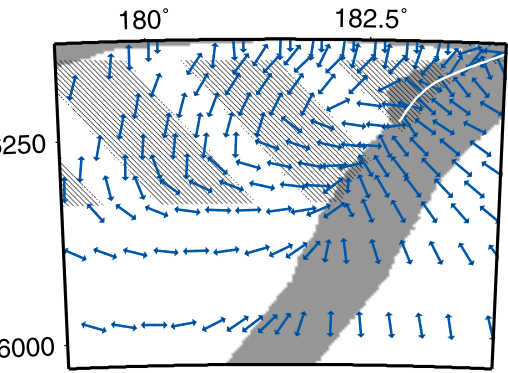

D. $50^{\circ}$

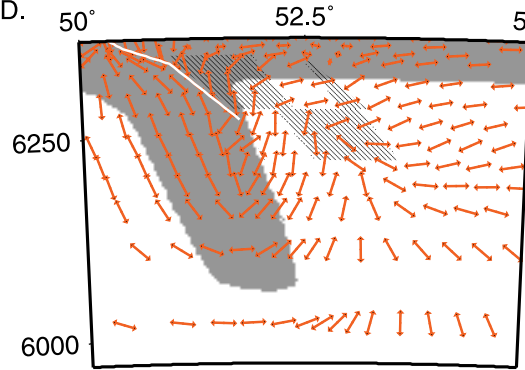

$55^{\circ} \mathrm{H}$.

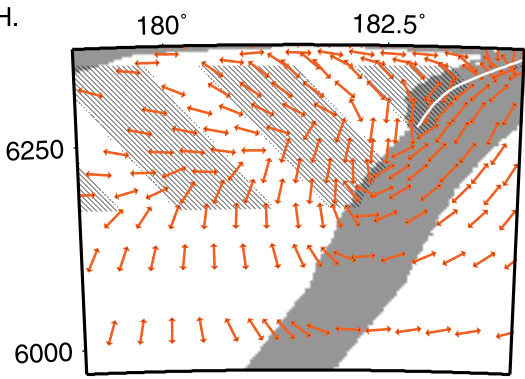

Figure 10. Comparison of Central Aleutians (CA) model 4, (a-d) and Tonga-Kermadec (TK), (e-h) subduction zone model. (a, e) Cross section of observed (black-thick line) and predicted (red-thin line) geoid at $182^{\circ}$ (CA) and $28^{\circ} \mathrm{S}(\mathrm{TK}) .(\mathrm{b}, \mathrm{f})$ Cross sections of observed (black-thick line) and predicted (red-thin line) topography. In the profiles the observed geoid or topography is shifted to align with the predicted topography or geoid at the northern (CA) or eastern (TK) boundary of the model. (c, g) Principal compression stress directions projected into the plane of the cross section (blue). Location of slab and LVW indicated by shaded and hatched regions, respectively. (d, h) Principal tension stress directions projected into the plane of the cross section (red).

tory of the subduction zone including several episodes of back-arc spreading and slab roll-back and the presence of other slabs within the model domain, but not included in the flow models, make it more difficult to match the geoid and topography at distances greater than $1000 \mathrm{~km}$ from the trench. However, shallow bathymetry extending more than $1500 \mathrm{~km}$ from the trench on the overriding plate and active back-arc extension require a much broader low viscosity region extending beyond the island arc and back-arc spreading center and a broader low density region extending at least $800 \mathrm{~km}$ from the trench, in contrast with the results for the Central
Aleutians (Figures 10a-10d, Central Aleutians; Figures 10e-10h, Tonga-Kermadec). The low viscosity and low density regions extend from $20 \mathrm{~km}$ to $200 \mathrm{~km}$ in depth and the density anomaly is $-20 \mathrm{~kg} / \mathrm{m}^{3}$ (Figure 9). In addition, the density anomaly due to the slab for the Tonga-Kermadec model was reduced by a factor of 1.3 relative to the background thermal model, in order to match the short to intermediate wavelength amplitude of the geoid above the trench. A large misfit with the amplitude of the geoid above the trench, (30$40 \mathrm{~m}$ greater than observed) was found for a model with the same viscosity structure and denser slab. 
[28] The orientation of stress within the top of the slab at shallow depths $(100-200 \mathrm{~km})$ in the TongaKermadec model is neither in down-dip compression nor tension (Figure $10 \mathrm{~g}$ ). Instead, the principal compression axis are oriented $20-30^{\circ}$ shallower than the down-dip direction $\left(\sim 60-80^{\circ}\right)$, rotating to down-dip compression throughout the slab below $200 \mathrm{~km}$. The bottom of the slab at shallow to intermediate depths $(100-300 \mathrm{~km})$ is primarily in down-dip tension, although the principal tension axis are also rotated $10-20^{\circ}$ steeper than the downdip direction in the shallow $(100-200 \mathrm{~km})$ portion of the slab. In 2-D models across the TongaKermadec slab at $28^{\circ} \mathrm{S}$ with the same viscosity and buoyancy structure, down-dip compression occurred in the top of the slab at all depths, indicating that the 3-D geometry of the slab is influencing the orientation of stress [Billen and Gurnis, 2003]. In particular, we find that the principal tension directions have an along strike component, possibly caused by the change in depth of the slab along strike. None of the 3-D models for the Aleutians have a similar along axis component of the principal stress axis.

\section{Discussion}

[29] The processes associated with aqueous fluids fluxing into the wedge from the slab and their effect on rheology and buoyancy in the wedge provides a self consistent model for the complex set of observations at both the Central Aleutians and Tonga-Kermadec subduction zones. However, one question which remains is what controls the difference in the size of the LVW in these two subduction zones. The large low viscosity region in the Tonga-Kermadec models suggests that the low viscosity region may need to reach a critical size to modify flow sufficiently before back-arc spreading and slab roll-back will occur. This dependence on the size of the low viscosity region may contribute to the observed episodic nature of these processes in many subduction zones [Kroenke, 1984; Faccenna et al., 2001] and could create a positive feedback due to the additional change in buoyancy. If the LVW is caused by water from the slab, then the size and depth extent of the wedge will depend on both the amount of water leaving the slab, how deep the water can be carried down by the slab and how water is transported away from the slab.

[30] Dehydration of the slab may be a continuous process beginning at a depth of $50 \mathrm{~km}$ within the subduction zone and extending to depths greater than $300 \mathrm{~km}$ within the subducted slab [Schmidt and Poli, 1998]. The maximum depth to which dehydration extends depends on the temperature along the top portion of the slab. Warmer slabs will dehydrate at shallower depths, while older slabs may carry water into the transition zone. Therefore, the difference in the depth extent and size of the LVW in the Central Aleutian and TongaKermadec models may be controlled in part by the age of the subducting plate. In the Central Aleutians the age of subducting plate is currently $\sim 55$ Ma [Müller et al., 1993], while in the TongaKermadec subduction zone the age of the plate is between $\sim 80$ and $\sim 120$ Ma [Billen and Stock, 2000].

[31] A low viscosity region in the wedge creates a complex state of stress within the slab that differs significantly from the state of stress predicted by models without a weak wedge. In models with a uniform viscosity asthenosphere, flow in the wedge creates a strong component of down-dip tension which dominates the state of stress in the shallow portion of the slab [Vassiliou et al., 1984; Billen and Gurnis, 2003]. The low viscosity region changes the flow within the wedge, decoupling the slab from the surrounding flow and allowing deformation due to viscous flexure of the slab to control the orientation of principal stress directions.

[32] In both the Central Aleutian and Tonga-Kermadec models, the LVW creates a region of down-dip or near down-dip compression within the top $25-50 \mathrm{~km}$ of the slab between $100-300 \mathrm{~km}$ depth. In Tonga-Kermadec, where the slab is in contact with the higher viscosity lower mantle, this region widens to fill the entire width of the slab deeper than about $300 \mathrm{~km}$. Based on these results and previous 2-D models [Billen and Gurnis, 2003], the large variability in the stress states 
within the slab and overriding plate may be explained by the presence or lack of a low viscosity wedge, whether the slab is in contact with a high viscosity lower mantle and the relative strength of the slab.

[33] An LVW may be present in subduction zones with a slab in either down-dip compression or tension depending on the internal deformation of the slab. If the slab is strong, but weaker than the lower mantle, the slab will be in down-dip or near down-dip compression at all depths. However, if the slab is stronger than the lower mantle or is not in contact with the lower mantle, then the slab will be down-dip tension or only have a narrow region of near down-dip compression. In subduction zones without a LVW, the slab will be in downdip tension at shallow depths transitioning to down-dip compression if the slab is in contact with a stronger lower mantle. At the same time the stress state of the overriding plate will depend on the width of the LVW perpendicular to the slab, with wider low viscosity regions contributing to backarc extension.

[34] The final models presented for each subduction zone both include a low viscosity, low density region in the wedge. However, the size of this region and the magnitude of the density anomaly within the wedge differ, with a larger LVW and larger density anomaly inferred for the TongaKermadec subduction zone. These differences are consistent with the differences in the observed of state of stress in the slab and overriding plate, topography and geoid. These differences may also be consistent with other observations not used to constrain these models:

[35] 1. A LVW could contribute to slab roll-back by decoupling the slab from the wedge. Rapid slab roll-back is observed in the Tonga-Kermadec subduction zone modelled with a larger LVW, while the Central Aleutians has no roll-back.

[36] 2. Flow within the wedge increases in magnitude and includes an upward component of flow which could draw the residue of melting from beneath the back arc to beneath the island arc, leading to more extensive depletion and to the larger density anomalies (lower total density) inferred for the Tonga-Kermadec subduction zone.

[37] These processes depend on large amounts of aqueous fluids leaving the slab to be transported away from the slab into the overlying mantle, lowering the viscosity of the wedge and facilitating higher degrees of melting than would otherwise occur beneath the island arc or back-arc spreading center.

\section{Conclusions}

[38] Including a low viscosity and low density region in subduction zone models provides an explanation for several geophysical observations and is consistent with seismic observations and the geochemical processes occurring within the subduction zone. The instantaneous models used here do not enable us to test how the presence of a low viscosity region will affect the evolution of the slab, the wedge or the overriding plate in time. Of particular importance is to what extent a LVW contributes to back-arc spreading and slab rollback and why the slab density based on thermal models for the Tonga-Kermadec model is too high by a factor of 1.3. It is unclear what mechanism could decrease the effective density of the slab by this amount, and further modelling is needed to confirm this result. The results for the Central Aleutians suggest that the slab density may be slightly lower than the value used in our models, but the discrepancy is much less than found for the Tonga-Kermadec model and appears only at long $(>1000 \mathrm{~km})$ wavelengths. Timedependent flow models incorporating localized regions of low viscosity above the wedge which also evolve in time are needed to investigate the implications of these results on the dynamic evolution of the thermal structure within the slab-wedge system.

\section{Acknowledgments}

[39] We thank Don Anderson for helpful discussion on water within the mantle and Paul Asimow for help estimating the density anomalies within a wet subduction zone wedge. Calculations were carried out on the facilities of the Caltech Center for Advanced Computer Research (CACR). Supported 
by NSF grants EAR-9725629 and EAR-9814577. Contribution no. 8850, Division of Geological and Planetary Sciences, California Institute of Technology.

\section{References}

Abers, G. A., Three-dimensional inversion of regional P and A arrival times in the East Aleutians and sources of subduction zone gravity highs, J. Geophys. Res., 99, 4395-4412, 1994.

Astiz, L., T. Lay, and H. Kanamori, Large intermediate depth earthquakes and the subduction process, Phys. Earth Planet. Int., 53, 80-166, 1988.

Billen, M. I., and M. Gurnis, A low viscosity wedge in subduction zones, Earth Planet. Sci. Lett., 93, 227-236, 2001.

Billen, M. I., and M. Gurnis, Multiscale dynamic models of the Tonga-Kermadec subduction zone, Geophys. J. Int., in press, 2003.

Billen, M. I., and J. Stock, Origin and morphology of the Osbourn Trough, J. Geophys. Res., 105, 13,481-13,489, 2000.

Chase, C. G., Extension behind island arcs and motions relative to hot spots, J. Geophys. Res., 83, 5385-5387, 1978.

Cooper, A. K., D. W. Scholl, and M. S. Marlow, Plate tectonic model of the evolution of the Bering Sea Basin, Geol. Soc. Am. Bull., 87, 1119-1126, 1976.

Faccenna, C., F. Funiciello, D. Giardini, and P. Lucente, Episodic back-arc extension during restricted mantle convection in the central Mediterranean, Earth Planet. Sci. Lett., 187, 105-116, 2001.

Fujita, K., and H. Kanamori, Double seismic zones and stresses of intermediate depth earthquakes, Geophys. J. Int., 66, $131-156,1981$.

Grow, J. A., Crustal and upper mantle structure of the central Aleutian Arc, Geol. Soc. Am. Bull., 84, 2169 -2192, 1973.

Gurnis, M., L. Moresi, and D. Müller, Models of mantle convection incorporating plate tectonics: The Australian region since the Cretaceous, in The History and Dynamics of Global Plate Motions, Geophys. Monogr. Ser., vol. 121, edited by M. A. Richards, R. G. Gordon, and R. D. van der Hilst, pp. 211-238, AGU, Washington D.C., 2000.

Hasegawa, A., D. Zhao, S. Hori, A. Yamamoto, and S. Horiuchi, Deep structure of the Northeastern Japan Arc and its relationship to seismic and volcanic activity, Nature, 352, 683-689, 1991.

Hirth, G., and D. L. Kohlstedt, Experimental constraints on the dynamics of the partially molten upper mantle, 2, Deformation in the dislocation creep regime, J. Geophys. Res., 100, 15,441-15,449, 1995.

Hirth, G., and D. L. Kohlstedt, Water in the oceanic upper mantle: Implications for rheology, melt extraction and the evolution of the lithosphere, Earth Planet. Sci. Lett., 144, 93-108, 1996.

Houseman, G. A., and D. Gubbins, Deformation of subducted oceanic lithosphere, Geophys. J. Int., 131, 535-551, 1997.

Karato, S., Mapping water content in the upper mantle, in Subduction Factory, edited by J. Eiler, AGU, Washington, D. C., in press, 2003.
Kawakatsu, H., Downdip tensional earthquakes beneath the Tonga Arc: a double seismic zone, J. Geophys. Res., 91, 6432-6440, 1986.

Kelemen, P. B., G. Hirth, N. Shimizu, M. Spiegelman, and H. J. B. Dick, A review of melt migration processes in the adiabatically upwelling mantle beneath spreading ridges, Philos. Trans. R. Soc. London, 355, 283-318, 1997.

Kroenke, L. W., Cenozoic Tectonic Development of the Southwest Pacific, U.N. ESCAP CCOP/SOPAC Tech. Bull. 6, New Zealand, 1984.

Laske, G., and G. Masters, A global digital map of sediment thickness, Eos Trans. AGU, 78(17), Fall Meet. Suppl., F483m, 1997.

Lay, T., D. H. Christensen, L. Astiz, and H. Kanamori, Temporal variation of large intraplate earthquakes in coupled subduction zones, Phys. Earth Planet. Int., 54, 258-312, 1989.

Lemoine, F. G., S. C. Kenyon, J. K. Factor, R. G. Trimmer, N. K. Pavlis, and et al., The Development of the Joint NASA GSFC and NIMA Geopotential Model EGM96, tech. rep., NASA Goddard Space Flight Center, Greenbelt, Md., 1998.

McKenzie, D. P., Speculations on the consequences and causes of plate motions, Geophys. J. R. Astron. Soc., 18, 1-32, 1969.

Mei, S., The effect of water on the plastic deformation of olivine and olivine-basalt aggregates, Ph.D. thesis, Univ. of Minn., Minneapolis, 1999.

Moresi, L., and M. Gurnis, Constraints on the lateral strength of slabs from three-dimensional dynamic flow models, Earth Planet. Sci. Lett., 138, 15-28, 1996.

Moresi, L. N., and V. S. Solomatov, Numerical investigations of two-dimensional convection with extremely large viscosity variations, Phys. Fluids, 9, 2142-2162, 1995.

Morris, J. D., W. P. Leeman, and F. Tera, The subducted component in island arc lavas: Constraints from Be isotopes and B-Be systematics, Nature, 344, 31-36, 1990.

Müller, R. D., J. Y. Royer, and L. A. Lawver, Revised plate motions relative to the hotspots from combined Atlantic and Indian hotspot tracks, Geology, 21, 275-278, 1993.

Müller, R. D., W. R. Roest, J. Y. Royer, L. M. Gahagan, and J. G. Sclater, Digital isochrons of the world's ocean floor, J. Geophys. Res., 102, 3211-3214, 1997.

Phipps-Morgan, J., The generation of a compositional lithosphere by mid-ocean ridge melting and its effect on subsequent off-axis hotspot upwelling and melting, Earth Planet. Sci. Lett., 146, 213-232, 1997.

Rigden, S. M., T. J. Ahrens, and E. M. Stolper, Densities of liquid silicates at high pressures, Science, 226, 1071-1074, 1984.

Roth, E., D. Wiens, and D. Zhao, An empirical relationship between seismic attenuation and velocity anomalies in the upper mantle, Geophys. Res. Lett., 27, 601-604, 2000.

Schmidt, M. W., and S. Poli, Experimentally based water budgets for dehydrating slabs and consequences for arc magma generation, Earth Planet. Sci. Lett., 163, 361-379, 1998.

Scholl, D. W., and R. H. Herzer, Geology and resource potential of the Southern Tonga Platform, in Geology and Geophysics of Continental Margins, AAPG Memoir, edited by 
J. S. Watkins, F. Shiqiang, and K. J. McMillen, vol. 53, chap. 9, pp. 139-156, Am. Assoc. of Petrol. Geol., Tulsa, Okla., 1992.

Scholz, C. H., and J. Campos, On the mechanism of seismic coupling and back arc spreading at subduction zones, J. Geophys. Res., 100, 22,103-22,115, 1995.

Schroeder, W., The empirical age-depth relation and depth anomalies in the Pacific Ocean Basin, J. Geophys. Res., 89, 9873-9883, 1984.

Seno, T., and Y. Yamanaka, Arc stresses determined by slabs: Implications for mechanisms of back-arc spreading, Geophys. Res. Lett., 25, 3227-3230, 1998.

Simons, M., Localization of gravity and topography: Constraints on the tectonics and mantle dynamics of Earth and Venus, Ph.D. thesis, Mass. Inst. of Technol., Boston, Mass., 1996.

Sleep, N. H., Stress and flow beneath island arcs, Geophys. J. Int., 42, 827-857, 1975.

Stolper, E., and S. Newman, The role of water in the pertogenesis of Mariana Trough magmas, Earth Planet. Sci. Lett., 121, 293-325, 1994.
Tatsumi, Y., M. Sakayuma, H. Fukuyama, and I. Kushiro, Generation of arc basalt magmas and thermal structure of the mantle wedge in subduction zones, J. Geophys. Res., $88,5815-5825,1983$.

Vassiliou, M. S., B. H. Hager, and A. Raefsky, The distribution of earthquakes with depth and stress in subducting slabs, J. Geodyn., 1, 11-28, 1984.

Worrall, D. M., Tectonic History and the Bering Sea and the Evolution of Tertiary Strike-Slip Basin of the Bering Shelf, Geol. Soc. of Am., Boulder, Colo., 1991.

Zhao, D., A. Hasegawa, and S. Horiuchi, Tomographic imaging of $\mathrm{P}$ and $\mathrm{S}$ wave velocity structure beneath Northeastern Japan, J. Geophys. Res., 97, 19,909-19,928, 1992.

Zhong, S., and M. Gurnis, Role of plates and temperaturedependent viscosity in phase change dynamics, J. Geophys. Res., 99, 15,903-15,917, 1994.

Zhong, S., M. Gurnis, and L. Moresi, Role of faults, nonlinear rheology, and viscosity structure in generating plates from instantaneous mantle flow models, J. Geophys. Res., 103, 15,255-15,268, 1998. 